Journal of Information Technology and Digital World (2020)

Vol.02/ No. 04

Pages: 221-228

https://www.irojournals.com/itdw/

DOI: https://doi.org/10.36548/jitdw.2020.4.006

\title{
Augmented Reality in Education
}

\author{
Pallikonda Subhashini $^{1 *}$, Raqshanda Siddiqua ${ }^{2}$, Aitha Keerthana ${ }^{2}$, Pamu Pavani $^{2}$ \\ ${ }^{1}$ Assistant Professor, Department of Computer Science and Engineering, Maturi Venkata Subba Rao \\ Engineering College, Osmania University, Hyderabad, India. \\ ${ }^{2}$ Department of Computer Science and Engineering, Maturi Venkata Subba Rao Engineering College, \\ Osmania University, Hyderabad, India. \\ E-mail: *subhashini_cse@mvsrec.edu.in
}

\begin{abstract}
Gaining from books is an unremarkable and latent cycle. The content and images in the books are most certainly not interactive; this prompts the basic barricades to learning looked by students, for example, constraints in comprehending the hypothetical ideas, absence of explanatory, basic reasoning. These detours are overwhelmed by computerized books, however paper-based books are frequently favored over computerized books due to their adaptability and portability. In this paper, we present a remarkable arrangement that utilizes augmented reality to make the learning measure more interactive and fascinating. The application when focused on text or image shows significant 3-dimensional(3D) model or video on the smart phone screen. The application gives some assistance to the students by encouraging them to learn new ideas utilizing graphical guide. Aside from utilization in schooling, it can likewise be utilized in the field of commercial, the travel industry, gaming, medication.
\end{abstract}

Keywords: Augmented Reality; education; learning.

\section{INTRODUCTION}

Table 1: Abbreviations

\begin{tabular}{|c|c|}
\hline Abbreviations/Acronyms & Definitions \\
\hline PC & Personal Computer \\
\hline AR & Augmented Reality \\
\hline SDK & Software Development Kit \\
\hline API & Application Programming Interface \\
\hline IDE & Integrated Development Environment \\
\hline
\end{tabular}

In our technology driven world, the paper book has been supplanted by electronic gadgets — Kindles and Nooks, and even, reading on your PC or smart phone. Old fashioned molded books are not, at this point seen as functional. There are issues if youngsters sitting at their PC/smart phone for longer timeframes than they are right now doing. Due to the pandemic circumstance made by COVID-19 infection, youngsters today are going through a long time on YouTube, on the web classes and this is certifiably not a solid movement for any individual of any age. We are strongly bound to the home and there is no other way yet acknowledge the reality and proceed with classes on the web, however we can even now lessen the screen time by utilizing paper books, however paper-based books are not interactive. The electronic type of the book is professed to help different sort of mixed media which make the perusing experience more fascinating. Be that as it may, the actual book is even more favored as contrasted with the electronic one. This is a result of the adaptability, portability. Consequently, we propose to develop an application that utilizes the idea of augmented reality for educational purpose in the form of Augmented Reality (AR) Books. Augmented Reality is a technology that superimposes a computer-generated image on a user's perspective on this present reality, in this way giving a composite view. This arrangement of AR Books will empower the user to float the camera on any page and recognize the content on it to acquire more intuitive and augmented data. This will make physical books more interactive. Thus, AR Books additionally give us both the benefits and actual book, for example, portability and digital books which give a clarification of every idea. By methods for AR books, students can comprehend a point given in a book without much involvement of electronic screen. It is an application where no typing or searching is needed for getting data. The interactivity aspect of this application like demonstrating the 3D model permits the user to 
Journal of Information Technology and Digital World (2020)

Vol.02/ No. 04

Pages: 221-228

https://www.irojournals.com/itdw/

DOI: https://doi.org/10.36548/jitdw.2020.4.006

comprehend the idea from each point. Applications with School Textbooks, Restaurant menu cards, Newspaper Advertisements, Touristic Guides and Specialized and Professionals books can be performed.

\section{MOTIVATION}

Legault, Green-Demers, and Pelletier, [1] reported one of the most prominent academic problems plaguing today's teenage youth is a lack of motivation toward academic activities. This is predominantly a result of the instructional techniques that don't address the issues of the students. There is an absence of inventive utilization of technology and dynamic cooperation of students where learning is worried, moreover; there are numerous students who have issues in envisioning and understanding in schools. Students need more important communications, for example, the utilization of Augmented reality (AR) in homeroom climate as opposed to the customary technique itself. Actual book generally furnishes students with non- vivid involvement in absence of inspiration components such as consideration, certainty, and even fulfillment. Augmented reality permits students to see the real world and have absolute drenching experience. Augmented reality technology can possibly offer students with 3D introductions and intuitive encounters that are more engaging than digital native learning. The energizing introductions and encounters in AR technology will increment inspiration in students.

\section{PROPOSED METHOD}

"The capacity to learn is a skill", is appropriately said by Brian Herbert. Learning or seeing any idea under the sun should be made interesting and synergistic. This will ultimately guarantee that the user has his/her complete consideration and can get a handle on things at a higher rate. The equivalent is being joined in the proposed application. The application depends on the idea of augmented reality. It fundamentally rearranges the learning measure for students. The basic thought is that the smart phone will go about as the vehicle for association with the book. To begin with, the user must install the augmented reality application on his/her smart phone. The user will likewise require a reading material from which he/she is contemplating. While concentrating from the paper book, the user may discover a few ideas or images hard to comprehend. He/she may even need extra data about the equivalent. All things considered; the user can run the proposed application on his/her smart phone. The application will begin the camera module and empower the gadget camera. The user can float the camera over the image, which is perceived utilizing the image target database. The image targets database stores all the images as image targets. At whatever point a user runs over any of these target images through the application, it will be perceived and distinguished. When the image is recognized, extra data about the image will be made accessible to the user.

\section{DESIGN AND IMPLEMENTATION}

To execute this application, different devices and advancements are required. A few methodologies exist to make Augmented Reality applications. A marker less image and text-based methodology are utilized wherein an image or text is perceived hereupon the relating data is enlarged. After examination on advancements accessible to serve the reason, Vuforia library was chosen. Vuforia is an Augmented Reality Software Development Kit (SDK) for smart phones that empowers the production of Augmented Reality applications. It utilizes Computer Vision technology to perceive and track planar images (Image Targets) and basic 3D articles, for example, boxes, progressively. The Vuforia SDK upholds an assortment of 2D and 3D target types including marker less Image Targets, 3D Multi-Target setups, and a type of addressable Fiduciary Marker known as a Frame Marker. Vuforia gives Application Programming Interfaces (API) in C++, Java, Objective-C++ (a language using a mix of $\mathrm{C}++$ and Objective-C sentence structure), and the .Net dialects through an expansion to the Solidarity game motor. Thusly, the SDK upholds both local improvement for iOS and Android while additionally empowering the improvement of AR applications in Unity that are without any problem convenient to the two stages.

\subsection{SETTING UP VUFORIA}

To begin, Vuforia's Developer Portal is set up and an account is made. When signed in, a developer page is accessible. A license key fills in as an ID to make an application in Unity utilizing Vuforia. This license key is made on the developer page with the assistance of a "License Manager". Next, the "Target Manager" is utilized to add Image Target in Solidarity. This is finished by adding an Image Target database and filling in the subtleties. Images are added to the recently made database. Vuforia upholds different sorts of targets like a single image, cylindrical, cuboidal, 3D image

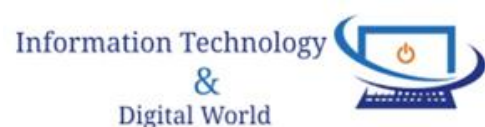

Digital World 
Journal of Information Technology and Digital World (2020)

Vol.02/ No. 04

Pages: 221-228

https://www.irojournals.com/itdw/

DOI: https://doi.org/10.36548/jitdw.2020.4.006

and so forth in conclusion, this image target database is downloaded for bringing into Unity. This is finished with the assistance of the "Download Dataset".

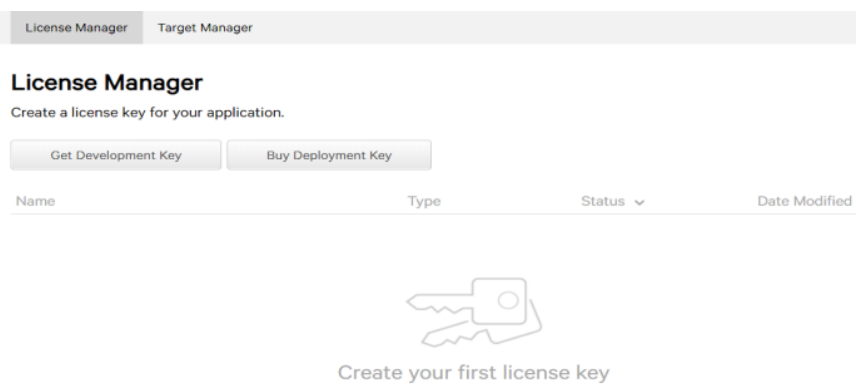

Figure 1. License Manager

Figure. 1 shows the Vuforia Developer Portal where the license keys can be managed, and the targets can be uploaded. Image Targets represent images that Vuforia Engine can distinguish and track. The Engine recognizes and tracks the image by contrasting extracted natural features from the camera image against a known target resource database. When the Image Target is recognized, Vuforia Engine will track the image and augment your content flawlessly utilizing best in market image tracking technology. Vuforia first distinguishes "feature points" in the target image and afterward utilizes the information to look at the features in target image and the receiving frame from camera.

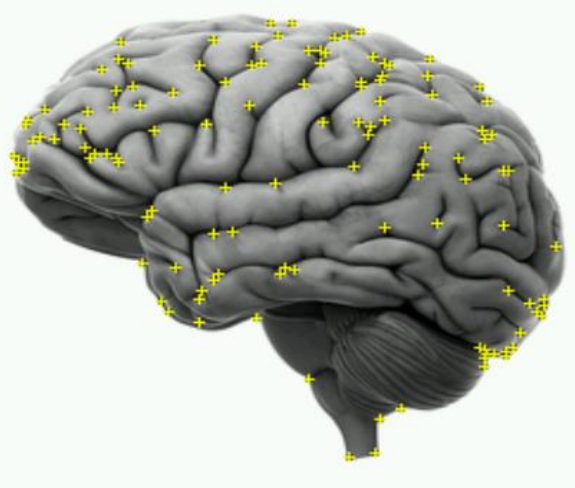

Figure 2: Feature points on brain image

\subsection{INTEGRATING WITH UNITY}

Unity is a cross-platform application engine developed by Unity Technologies which provides a framework for designing game or app scenes for 2D and 3D. "AR Camera" is an Augmented Reality camera prefab from Vuforia. Image Target is added to the scene which is be found in the "Prefabs" folder.

\subsection{MODEL AUGMENTATION}

After the system is prepared with Image and Text recognition modules, a 3D Model is augmented over the recognized content or media. It is found under "Model" folder in Assets. For the model to show up over Image Target, it is made an offspring of image Target. This is essentially done by hauling the model prefab in the Hierarchy panel. At whatever point the Image Target is recognized by a smart phone's camera, all the offspring of the target additionally show up together. The equivalent is additionally performed for augmenting model over a text. Figure 3 shows the application augmenting a 3D skeleton model on the recognized text of " skeleton ".

Information Technology

\&

Digital World 
Journal of Information Technology and Digital World (2020)

Vol.02/ No. 04

Pages: 221-228

https://www.irojournals.com/itdw/

DOI: https://doi.org/10.36548/jitdw.2020.4.006

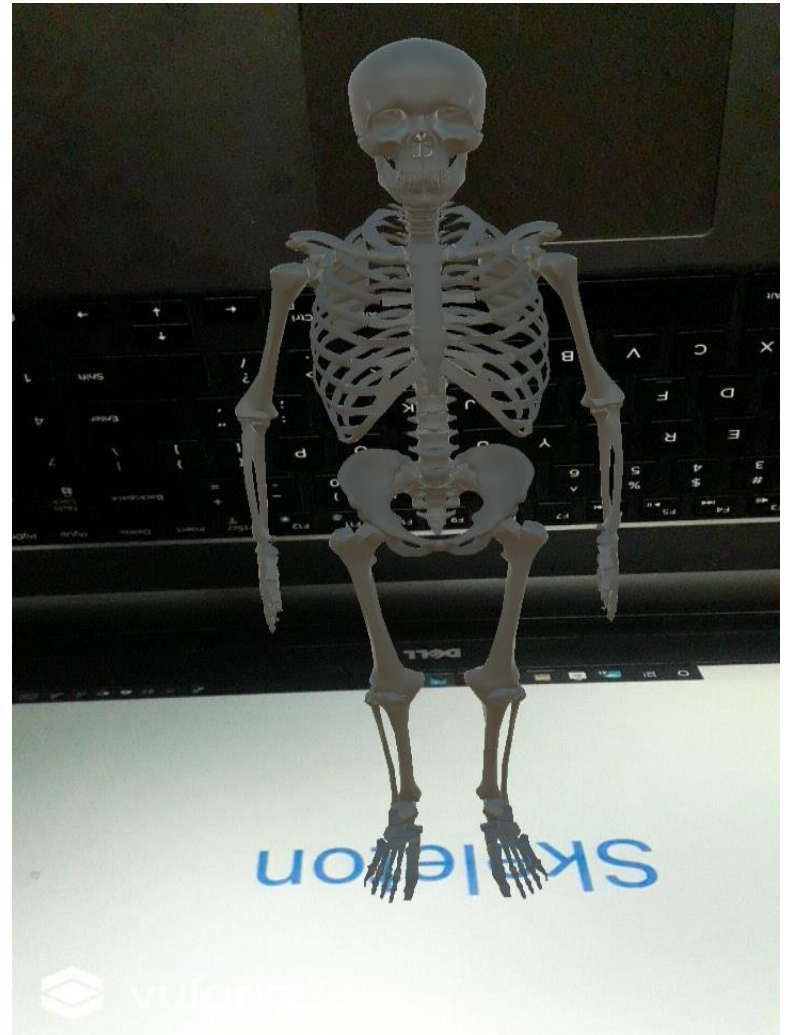

Figure 3. Model Augmented on text

\subsection{VIDEO AUGMENTATION}

For augmenting a video on an Image target, the Advanced Subjects of Vuforia are imported into Unity. The video is added over the image by utilizing the video playback prefab on image target. Various components are added, for example, trackable event handler, play video controls, tap handler, menu options and so forth. At last, the Video Prefab under Image target is chosen, also, a play video component is added. This guarantees that a video plays when the image or text is selected.

\subsection{DEPLOYING THE SYSTEM}

For developing the system, the main advance is to deploy it on platforms which make it usable for users. Unity gives the upside of deploying the application on various platforms, for example, android, iOS and so forth. Utilize the Build Settings window to pick your target platform, change the settings for your application build, and start the build process.

\subsection{RUNNING THE APPLICATION}

After deploying the application, a package is made accessible for installation. After installing the package, the application will begin, and the camera module will start. At that point, the user should just drift the camera over the given text or image and the relating graphics will be rendered.

Information Technology

$$
\text { \& }
$$

Digital World 
Journal of Information Technology and Digital World (2020)

Vol.02/ No. 04

Pages: 221-228

https://www.irojournals.com/itdw/

DOI: https://doi.org/10.36548/jitdw.2020.4.006

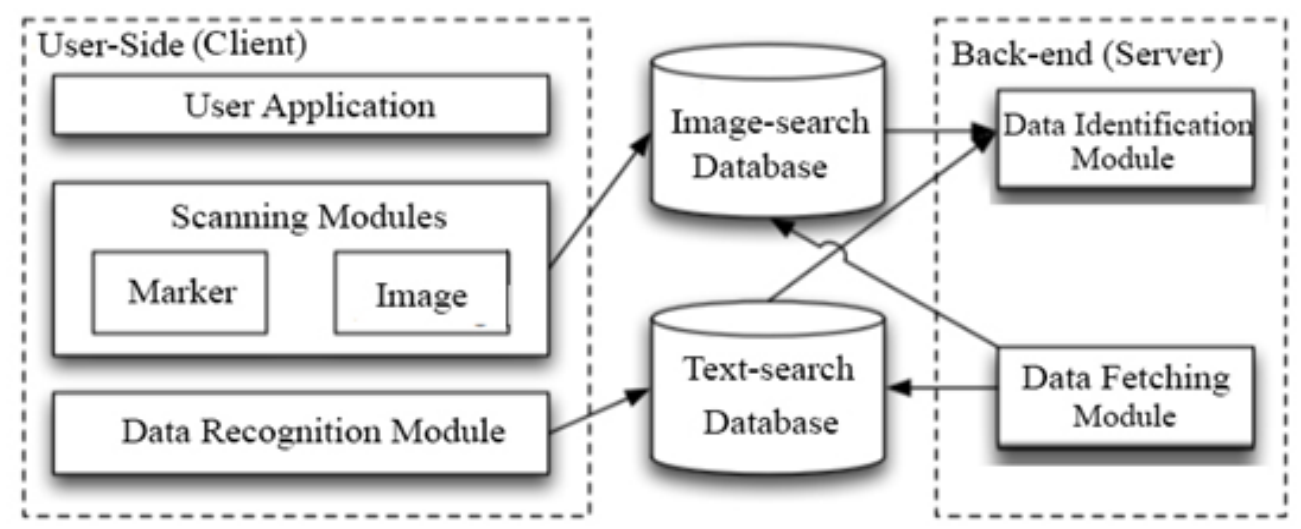

Figure 4. System Architecture

\section{TECHNOLOGIES USED}

\subsection{BLENDER 3D}

Blender is a free and open-source 3D computer graphics software product utilized for making animated films, visual effects, interactive 3D applications or computer games. Blender gives a wide range of modeling, texturing, lighting, animation and video post-processing functionality in one package. Through its open design, Blender gives crossplatform interoperability, extensibility, an amazingly small footprint, and a firmly integrated workflow. Blender is one of the most famous open source 3D graphics applications in the world.

Blender can be utilized to make 3D visualizations, stills as well as broadcast and film quality recordings, while the fuse of a real-time 3D engine allows for the creation of 3D interactive substance for stand-alone playback.

\subsection{UNITY 3D}

Unity 3D is a completely integrated development engine that gives rich out-of-the-case functionality to make games also, other interactive 3D content. Unity can be utilized to amass workmanship and resources into scenes and conditions; add lighting, sound, special effects, physics and animation; at the same time play test and edit games, and when prepared, publish to your picked platform, for example, PCs, iOS, Android, and so on In the other hand, the Vuforia extension for Unity empowers detection and following functionality in the Unity IDE and permits to effortlessly make AR applications and games.

\section{RESULTS}

The camera module is the first thing that begins when the application has begun, once it starts, it dynamically searches for text/image on the page as opposed to requiring a picture of it. After the required content is recognized, its corresponding 3D model or related data from the database is rendered. This data can be either 3D model or some images or even videos which comprehend the ideas which are attempted to clarify in every text or picture.

Information Technology \& Digital World 
Vol.02/ No. 04

Pages: 221-228

https://www.irojournals.com/itdw/

DOI: https://doi.org/10.36548/jitdw.2020.4.006
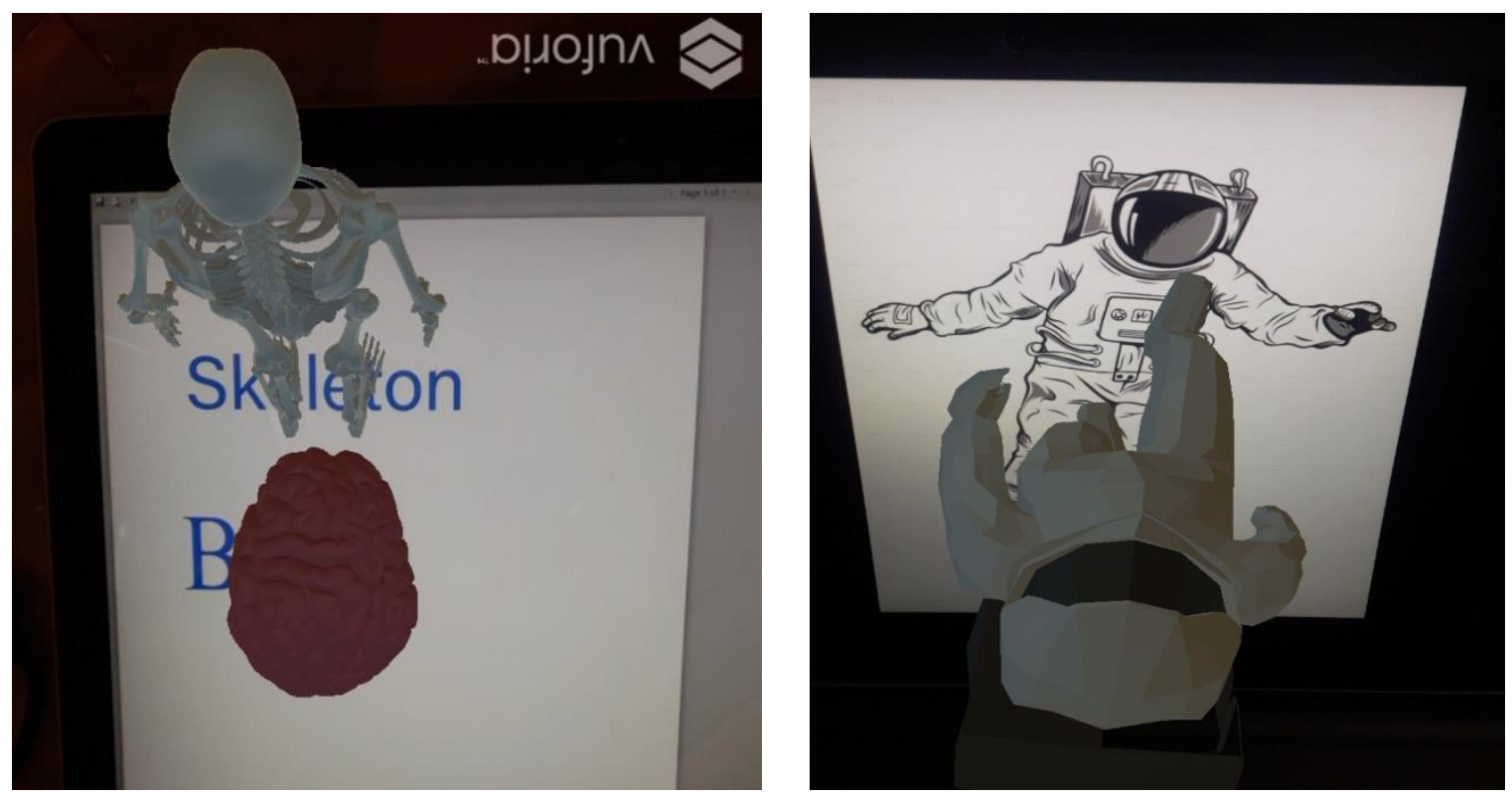

Figure 5: Outputs

\section{CONCLUSION}

The system "Augmented Reality in Education" is actualized where a user can hover a camera over a page also, get augmented data, for example, 3D Model, video or an explanation about that page. It is where no typing or searching is needed for getting data. The application gives some assistance to the children by encouraging them to learn new ideas utilizing graphical aid. Since the application can be conveyed on any smart phone, a student can utilize it according to his/her comfort. Additionally, there is no requirement for any additional support for this application consequently making it a prudent arrangement. The interactivity part of this application like demonstrating the 3D model permits the user to comprehend the idea from each point. The application can be extended further and utilized for different age bunches for not just adapting yet additionally helping the users to visualize and grasp things quicker. It gives an exceptional and intriguing method of learning and comprehension of obscure ideas.

\section{References}

[1] Legault, L., Green-Demers, I., \& Pelletier, L. (2006). Why Do High School Students Lack Of Motivation In Classroom? Toward an Understanding of Academic Amotivation and The Role Of Social Support. Journal of Educational Psychology, 98(3), 567582

[2] Soham Mehta \& Bhakti Raichura" Interactive Virtual Assistance using Projected Augmentation" -DJASCII published by Excel Publications with ISBN 9789385777431

[3] Stephane Magnenat, Dat Tien Ngo, Fabio Z' und, Mattia Ryffel, Gioacchino Noris, Gerhard Rothlin, “ Alessia Marra, Maurizio Nitti, Pascal Fua, Fellow, IEEE, Markus Gross, Robert W. Sumner- "Live Texturing of Augmented Reality Characters from Colored Drawings

[4] Augmented reality by David Johnson www.eng.utah.edu/ cs6360/Lectures/Augmented\%20Reality.ppt

[5] Ho-Sub Ryu \& Hanhoon Park- "A system for supporting paper-based augmented reality”,2015

[6] Muhamad Fadhil Norraji \& Mohd Shahrizal Sunar- "wARna -Mobile-based Augmented Reality Colouring Book", Interactive Digital Media (ICIDM) ,2015

[7] Billinghurst, M.; Kato, H.; Poupyrev, I. "The MagicBook -moving seamlessly between reality and virtuality," Computer Graphics and Applications, IEEE, vol.21, no.3, pages 6-8, May/Jun 2001

[8] Rabbi, I., \& Ullah, S. (2014, December). The applications of markerbased tracking in semi-controlled environment. In Open Source Systems and Technologies (ICOSST), 2014 International Conference on (pp. 82-86). IEEE.

Information Technology \& Digital World 
Journal of Information Technology and Digital World (2020)

Vol.02/ No. 04

Pages: 221-228

https://www.irojournals.com/itdw/

DOI: https://doi.org/10.36548/jitdw.2020.4.006

[9] T. I. Saso, K. Iguchi, and M. Inakage. Little red: storytelling in mixed reality. Proceedings of SIGGRAPH "03 Sketches \& Applications, pages 1-1, New York, NY, USA, 2003. ACM 
Journal of Information Technology and Digital World (2020)

Vol.02/ No. 04

Pages: 221-228

https://www.irojournals.com/itdw/

DOI: https://doi.org/10.36548/jitdw.2020.4.006

\section{Authors' Biography}
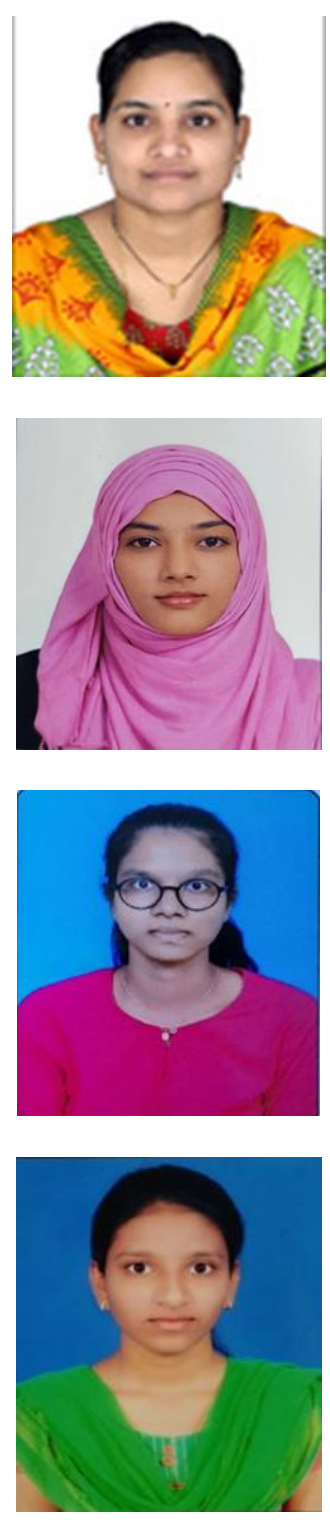

Subhashini Pallikonda received her M.Tech in Computer Science and Engineering from Osmania University (2013). She is also pursuing her Ph.D. in Computer Science and Engineering from Adikavi Nannaya University. She has published 5 papers ( 2 conferences and 3 journals) She is currently working as an Assistant Professor at Maturi Venkata Subba Rao Engineering College with an experience of over 16 years. She is interested in Cloud Computing, Distributed Computing, IRS, Data Mining and Network Security. She has taught C, C++, Data Structures, Data communications, DBMS, OOSD, Distributed Systems, Distributed Computing and ADB.

Raqshanda Siddiqua holds a B.E in Computer Science and Engineering from Osmania University (2020). She is currently working as Associate Professional Software Engineer at DXC Technology. She has been an active member of Computer Society of India (CSI) and Institute of Electrical and Electronics Engineers (IEEE) and has done various outreach programs and received the best outreach award (2018) from IEEE Hyderabad Section. She is a certified full stack java developer. She is interested in Augmented Reality, Cloud Computing, Full Stack Development.

Keerthana Aitha holds a B.E in Computer Science and Engineering from Maturi Venkata Subba Rao Engineering college. She is currently working as Info Developer at Hewlett Packard Enterprise. She is also member of Computer Society India (CSI) and has received the best outreach award (2018) from IEEE Hyderabad Section. She is interested in Computer Networks, Artificial Intelligence, Augmented Reality, Database Management Systems.

Pavani Pamu holds a B.E in Computer Science and Engineering from Maturi Venkata Subba Rao Engineering College affiliated to Osmania University (2020). She is currently working as Programmer Analyst Trainee in Cognizant Technology Solutions India Private Limited. She is interested in Java Programming. 